\title{
O REGIONALISMO REVISITADO: UMA VISÃO DE ÁNGEL RAMA
}

\section{Vera Lúcia Romariz Correia de Araújo (*)}

Resumo: Este artigo analisa a obra crítica do uruguaio Ángel Rama a partir das categorias de regiões culturais e transculturação narrativa aplicadas ao romance na América Latina.

Palavras-chave: Oralidade; cultura; narrativa; assimetria

Na década de 80, o professor Antônio Arnoni Prado apresentou-me a parte do pensamento do crítico uruguaio Ángel Rama' contida em seu livro Cidade das Letras (1985); nesta obra, Rama defende a idéia de que uma fundamental contradição configurou a construção das cidades americanas, estruturadas dicotomicamente. Uma face seria a da cidade oficial, de configuração arquitetônica e linguiística com influência européia, produtora do texto escrito e normativo da cultura e religião oficial, enquanto a outra, a das periferias urbanas na América Latina, seria mística e difusa, de formação espacial labiríntica, pobre, subalterna em relação à cidade letrada, e de origem marcadamente rural, apesar de integrar geograficamente o mesmo espaço urbano. A cidade não letrada voltase para seus mitos, suas raízes africanas ou indígenas, seus labirintos urbanos e verbais. Nesta, viveriam as populações marginalizadas. representadas verbalmente com os signos da oralidade; na outra, oficial, as elites americanas, constituídas como a civilização da escriti, do significante que teima em desprender-se dos significados socioculturais da América Latina. Na cidade mais americana, os dialetos, os crioulos ou os jargões nordestinos; na eurocêntrica, ritos oficiais, normas jurídicas que, paradoxalmente, não são nossos mas teimam em falar por nós a partir de um sistema de pensamento

Professora e pesquisadora da Universidade Federal de Alagoas: doutora em Letras pela Ufpb.

1 Aguiar, Flávio e Guardini, Sandra (orgs). Ángel Rama; literatura e cultura na América Latina. São Paulo: Edusp, 2001. Trata-se da mais complela tradução de textos do autor em língua portuguesa. 
gestado em outro contexto ${ }^{2}$. Mário de Andrade, a respeito dessil sobrevivência popular nos grandes núcleos urbanos cosmopolitas, observa que manifestações orais importantes sobrevivem nas periferias das grandes cidades, assim como Darcy Ribeiro ${ }^{3}$ nos alertou para o fato de as populações negras e índias formarem, paulatinamente, o subproletariado das grandes cidades.

Essa dicotomia no interior da cidade latino-americana ajudanos a entender certa dialética no interior do pensamento de Rama em relação a muitos de seus famosos conceitos, como, por exemplo, o de transculturação narrativa, em que afirma que os grandes escritores latino-americanos, que nomeia transculturadores, representam dialeticamente sua cultura, dialogando com essas duas faces da cidade e com o interior do país, mas a partir de técnicas vanguardistas apreendidas nas metrópoles, no contato com as culturas estrangeiras de "prestígio"econômico e intelectual. Cabe, por exemplo, nesse pensamento sobre a Cidade das letras, uma revisão dos limites geográficos das fronteiras, pois o mundo não-citadino, menos desenvolvido tecnologicamente que o urbano, tem ramificações simbólicas nas periferias das grandes cidades, o que faz repensar o atrelamento do urbano a uma modernidade apenas cosmopolita, integrada à modernização, e um regional rural, interiorano, representando romanticamente os rincões afastados das metrópoles. É nessa intersecção entre o moderno das cidades e o particular do campo que se insere o olhar de Rama, atento a essa composição contraditória das culturas latino-americanas, buscando, com seu olhar afiado de crítico, romancistas que representem esse complexo contraditório e híbrido que é nossa cultura.

São quatro os escritores da América Latina que o autor nomeia transculturadores, pois, segundo ele, os "quatro levaram a fundo o projeto transculturante, impondo no estrito universo artístico obras fundamentais que estão irrigadas pelos valores de suas culturas regionais" (Rama, 2001, p.233);trata-se de José Maria Arguedas, Juan Rulfo, Guimarães Rosa e Gabriel Garcia Márquez. Em Arguedas, Rama registra a contribuição importante de posições críticas que defende no Primer Diário, espécie de manifesto em que defende

Cl Holanda. Sérgio Buarque. Raízes do Brasil. 20.ed. Rio de Janeiro, 1988.

Riheiro, Darcy. O povo brasileiro. São Paulo: Companhia das Letras. 1994. 
idéias regionais e critica o suposto universalismo que alguns escritores do continente adotam, centrados em uma visão eurocêntrica já questionada inclusive na Europa por Paul Valéry e, em seguida, pelos surrealistas. Nesse trabalho, Arguedas propõe a visão próxima da concepção da cidade iletrada de Rama para subsidiar novas técnicas literárias na narrativa, como um modo "obscuro, intuitivo, certeiro. coloquial e até próximo com que se observa a realidade" (p.234).

É assim, vendo a cultura latino-americana em sua dialética, que Rama desconstrói uma visão da América Latina com faces excludentes, atravessando uma questão central de parte de nosso Modernismo - o elogio da técnica e da industrialização -, quase sempre atrelado ao futurismo italiano e a suas ramificações políticas fascistas no Ocidente, ou um regional de base realista muito conservadora. com conteúdo e forma calcados em um modelo superado formal e ideologicamente. Quando, em 1972, em meio ao boom latino-americano na Europa, o crítico uruguaio escreve o famoso ensaio "Transculturação na narrativa latino-americana", traduzido pela primeira vez no Brasil para o jornal carioca Opinião, seu pensamento evolui no sentido de ver as marcas histórico-literárias dessa questão cultural, propondo uma revisão do regionalismo tradicional e, simultaneamente, trazendo um novo olhar sobre as vanguardas, que esquecem a cidade subalterna e sua herança rural, mas oxigenam a forma narrativa. Rama (2001, p.221) também questionará o modelo literário de base realista utilizado pelos regionalistas mais tradicionais, afirmando que

O romance regional havia elaborado suas formas sobre os modelos narrativos do naturalismo do século XIX adequando-os a suas necessidades expressivas, e se depara $[\ldots]$ então com o leque de recursos vanguardistas que [..] passarão a fecundar a narrativa fantástica [.. e e a realista-crítica das cidades $[\ldots]$ em concordância com uma cosmovisão fragmentada.

Parece-nos, a princípio, que a proposta de Rama tem algo de utópica: trazer a temática regionalista para um romance de vanguarda, renovando sempre o fazer literário com o experimentalismo cujo mérito de renovar o cânone da escrita é inegável. Simultaneamente estudioso confesso da América Latina e crítico literário arguto, esse uruguaio desaparecido tragicamente, em meio a ameaças de expulsĩo 
seguidas, tentou desarticular a dicotomia campo/ cidade, tradição regional/ experimentalismo narrativo.

Mas talvez o maior mérito de Rama tenha sido o de mostrar que um escritor fala, sempre, a partir de uma língua literária, e não the cabe fixar, etnograficamente, dialetos crioulos ou africanos $e$ indígenas, mas falar deles e com eles, construindo uma convenção artística que não reitera antropologicamente o diferente subalterno, mas o ilumina via linguagem crítico-poética. O compromisso de um escritor transculturador, para Rama, é primeiro, com seu projeto de escrita literária e, depois, com a expressão do complexo cultural latino-americano, não excluindo o diálogo com outras culturas centrais mas evitando o que Fernando Ortiz chamou de rigicle: cultural (etnocentrismo) ou aculturação excessiva. Apesar de sua proposta integradora da América Latina, Rama não desconhecia a força da convenção artística dos países centrais, o que nos lembra uma fala de Buarque de Holanda (1988, p.3) sobre o tema, quando não limita a noção de fronteira ao desenho geográfico.

Podemos construir obras excelentes, enriquecer nossat humanidade de aspectos novos e imprevistos, elevar it perfeição o tipo de civilização que representamos: o certo é que todo fruto de nosso trabalho ou de nossa preguiça parece participar de um sistema de evolução próprio de outro clima e de outra paisagem.

Essa visão crítica de que somos julgados a partir de convenções exógenas, influenciou uma discípula de Rama, a crítica chilena Ana Pizarro4, a propor que é tarefa do escritor latinomericano ressemantizar a convenção ocidental a partir de nossias matrizes orais, populares, indígenas e africanas. É nessa linha que se pode ler o modelo teórico de Rama: universal e local, sobretudo literário, comprometido com a América Latina e com seus diferentes internos e externos. A noção de duplicidade acompanhou Rama em toda sua vida e o conceito de dupla vanguarda, discutido por Candido. foi uma delas. Evidentemente a noção de dialética perpassa toda sua obra, mostrando-nos o que chamaríamos de pensamento em trilhos, pois era um intelectual de formação marxista, tendo sido o editor do semanário Marcha,perseguido pelo regime militar uruguaio.

Pizarro, Ana. De ostras y canibales. Santiago: Editorial Universidad de Santiago, 1994. 
A crítica ao Regionalismo do século XIX, em Ángel Rama, é acompanhada de uma forte revisão do Realismo social que pretendia fazer uma literatura só de conteúdos, sem a preocupação formal. Assim, ele propõe a manutenção da temática rural dos regionalistas e a forma experimental das vanguardas latino-americanas para complementar o conceito de transculturação narrativa, do qual Guimarães Rosa seria o melhor exemplo em língua portuguesa e Juan Rulfo o de língua espanhola no continente.

É com esse olhar reduplicado que Rama irá rever uma noção bastante polêmica entre nós, brasileiros, nordestinos: a do Regionalismo. Conceito que se fundou em uma concepção particularizante na Antropologia e na Literatura, e que teve seu ápice no século XIX, a reboque de uma forte onda de idéias nacionalistas, o elemento regional parece ter sido visto nessa época como o antípoda do universal, o que lhe conferiu um certo estigma de subsidiador de guetos culturais e lingüístico-literários. Textos regionalistas iniciais no Brasil, como O sertanejo, de Alencar, assim como toda uma tradição gaúcha posterior, parecia configurar-se com uma dicção diferenciadora que, tendendo para o particular, sugeria uma forma estranha de etnocentrismo rural, caboclo e anti-urbano. Se os regionalistas se consideravam defensores das regiões do país, espécies de cruzados de uma nacionalidade rural, os pensadores ou artistas cosmopolitas eram seus opositores, estigmatizados pelos locais/regionais como estrangeiros.

O Manifesto Regionalista do Recife, com Gilberto Freire à frente e seus seguidores diretos e indiretos ${ }^{5}$, constituiu exemplo dessa expressão local, regional, que traduzia idéias etnocêntricas a partir das paisagens interioranas e rurais.Para os regionalistas e nacionalistas exacerbados, filhos do mesmo ventre etnocêntrico e por vezes xenófobo, o urbano transformou-se em configuração a ser rechaçada como estranha ${ }^{6}$, espécie de convenção que não nos representaria

5 Cf ÁVILA, Janayna de Souza. Modernismo e regionalismo na década de 20 em Alagoas. Dissertação de mestrado. PPGLL, Ufal, Maceió, 2003. A autora faz um inédito levantamento dos textos críticos sobre o modernismo nos jornais alagoanos do período, mostrando o lugar predominantemente regionalista de autoria na composição dos textos.

6 Em Etrangers à nous-mêmes (Paris: Gallimard, 1998), Julia Kristeva dissecou, com erudição e em um panorama histórico e literário, o significado do termo estrangeiro a partir de uma releitura antropológica 
adequadamente. Mas Rama reconhece a grande contribuição dos regionalistas, como Gilberto Freyre e Arguedas, no sentido de trazerem para a literatura a cor local, dado fundante na visão de uma cultura como a latino-americana, cujas populações pobres vivem ou no interior ou na periferia da cidade letrada.E entende os motivos de certa rigidez regionalista inicial, pois

A crítica põe em circulação critérios classificatórios que opõem narrativa rural a narrativa urbana [...] distinção temática superficial [...] sugerindo uma hierarquia de estética [...] os escritores da transculturação mantêm-se apegados a seus meios rurais - campo e vilarejo conseguindo que as errantes populações do sertão, os adormecidos povoados tropicais voltem a ser partes legítimas da América latina (RAMA, 2001, p.232).

É com essa visão ampla sobre a própria crítica que Rama, utilizando o termo transculturação, de Fernando Ortiz, vai empreender uma revisão do Regionalismo, desarticulando o pensamento dicotômico sobre cultura do campo, cultura urbana e suas representações hierarquizadas e instaurando um olhar dialético sobre as relações de um escritor com sua cultura. Para Rama, os grandes escritores transculturadores da América Latina, como Juan Rulfo e Guimarães Rosa, captaram a dupla face (novamente o duplo) da cultura latinoamericana e a expressaram com os signos contemporâneos apreendidos nas cidades cosmopolitas, que dialogam constantemente com as culturas externas; assim, construíram estórias sobre os lugares mais distanciados da tecnologia urbana, mostrando em linguagem poética a dupla cidade americana. Esses grandes transculturadores saíram do vezo regionalista redutor que transcrevia o dialeto ou as especificidades linguísticas de outros estratos não-hegemônicos em tom exótico para, como um grande e plástico narrador, contar de dentro a história de sua complexa e contraditória cultura brasileira, uruguaia ou boliviana.

do ensaio $O$ estranho, de Freud, que parte da raiz alemã do termo (assustador) para entender o núcleo de estigma, nódoa e lacuna de identidade. Dialogando com a autora, Todorov escreveu duas fundamentais obras sobre o peso desse desenraizamento, avançando $\mathrm{cm}$ uma questão fulcral: o que muitos entendem como universal é, na verdade, um particular de cultura hegemônica, legitimado pelo uso. Assim,entre nós, o modelo greco-latino se tornou símbolo de universalidade, enquanto outros modelos, datados, seriam anti-universais. 
Quando Rama se dedica mais intensamente à discussão de uma espécie de super-regionalismo, caem por terra alguns elementos, como o excesso de localismo, entrando em cena o inevitável diálogo entre o local e o universal no interior das narrativas latinoamericanas.O que me parece claro nessa defesa de Rama de um Regionalismo, ainda que mais aberto, é uma certa defesa do elemento local na temática da literatura do continente, sem que o escritor abdique de convenções e experimentalismos vigentes no Ocidente e nos grandes centros urbanos, como São Paulo e Buenos Aires, onde a renovação do fazer literário desarticulava uma espécie de realismo em linguagem já superado pelo denso material de escritores como Guimarães Rosa, Juan Rulfo e Oliverio Girondo. A sempre densa discussão entre natureza e cultura, encetada por antropólogos como Lévi-Strauss, que trabalhou no Brasil, parece revitalizar-se no pensamento de Rama, que não parece querer resolver redutoramente a questão, mas dialetizá-la.

Assim,o ruralismo da tradição romântica coexistirá com uma escrita experimental, nos textos de Rosa, mostrando a tensa contradição de um país de rincões rurais e grandes edifícios, que fizeram a alegria dos primeiros modernistas, como Graça Aranha, extasiados diante da "luz, ar, ventiladores". Rama parece querer distanciar-se desse ufanismo diante da tecnologia que embalou os críticos de base futurista, com Marinetti e seu fascismo à frente e recuperar uma narrativa que mostre o caráter híbrido das culturas latino-americanas, rurais e cosmopolitas, desiguais e híbridas. A vida política de Rama, editor do semanário Marcha, de tendência marxista, faz que ele produza um modelo de pensamento que amplia, em muito, a noção de regional. Para ele, as regiões não são convenções intrapaís,pois a região amazônica e a gaúcha transpõem, do ponto de vista dos costumes e dos valores, as fronteiras de um único país latinoamericano.

Em um segundo nível, [..]a diversidade é acreditada pela existência de regiões culturais. Embora estas se perfilem extensas e nitidamente delineadas nos grandes países $[\ldots]$ A divisão em regiões, dentro de qualquer país, tem uma tendência multiplicadora que, em casos limites, produz. uma desintegração da unidade nacional [...] tal como ocorre com Guimarães Rosa quando tenta oferecer um perfil de sua Minas Gerais natal (RAMA, 2002, p.282). 
Percebo na noção de região de Rama uma desarticulação do conceito de nacionalismo e um propósito, quase uma militância, de uma integração latino-americana. Hoje, a crítica Ana Pizarro 7 pode ser considerada sua discípula, pois construiu um projeto de história literária da América Latina em três volumes, reunindo críticos como Candido, Adolfo Colombres, a própria Pizarro e Angel Rama, estudando questões de história e crítica literárias ${ }^{\mathrm{s}}$ e discutindo a relação entre a convenção artística dos textos e a referência cultural latino-americana, que configura e condiciona a especificidade do signo literário, adensando-o com os referentes históricos do continente.

Esse falar de dentro se acoplou a um movimento moderno de maleabilidade ${ }^{9}$ do plano enunciativo no romance moderno, pois vemos, com gradação visível, uma aproximação entre o nível lingüístico do narrador e o psiquismo e composição lingüística das personagens contemporâneas, como no conto OAOEOO, de Bernardo de Carvalho, em que o narrador fala como se fosse um menino de rua explorado por um artista desequilibrado e criminoso.

Revisitar o Regionalismo tradicional, apenas, ou o Modernismo de base futurista, para Angel Rama, é revisitar uma possibilidade crítica assentada em um conceito de cultura excludente; sua postura da Crítica Literária aponta para categorias analíticas que precisariam ser permanentemente contextualizadas no continente latino-americano, condicionando uma leitura da representação literária do elemento local que não abdica do universal, mas desconfia de que o Ocidente de influência européia detenha essa universalidade. Um regional latino-americano parece ser o projeto histórico-literário de Rama ou, para usar uma expressão de Candido, referindo-se a

7 Pizarro, Ana (org). Literatura,palavra e cultura. São Paulo/Campinas: Editora do memorial da América Latina, 2000.

8 Em entrevista concedida à revista da Fundação de pesquisa em Alagoas. Pizarro faz questão de distanciar-se dos Estudos Culturais e dizer-se uma estudiosa de questões literárias e culturais da América Latina.

9 Em nossa tese de doutoramento (Araújo, Vera Lucia Romariz Correia. Palavra de deuses, memória de homens. Diálogo de culturas na ficção de Adonias Filho. Maceió: Edufal, 2001) propusemos a categoria critica do narrador móvel, cuja mobilidade teria como parâmetro a mudança cultural, estabelecendo uma similaridade entre a retórica do texto e o contexto onde a convenção se gesta. 
Guimarães Rosa, um super-regionalismo ${ }^{10}$, que transcende os limites da nação, mas a ela pode eventualmente voltar. Para concluir, gostaria de lembrar que para Rama a cultura não deveria ser vista pelos intelectuais latino-americanos como ornamento de poucos, mas como um princípio integrador e aglutinante, representação das cidades orais e letradas, ricas, híbridas e legítimas como a sua América Latina espaço de paixão crítica permanente.

10 Cf.Figueiredo, Eurídice. Construcciones identitarias: Aimé Césaire, Édouard Glissant y Patrick Chamoiseau .In:Pizarro, Ana (compiladora). El archipiélago de fronteras externas. Santiago: Editorial Universidad de Santiago, 2002. 